\title{
REVENUE EFFICIENCY IN HIGHER EDUCATION INSTITUTIONS UNDER IMPERFECT COMPETITION
}

\author{
Geraint Johnes \\ Lancaster University Management School \\ Lancaster LA1 4YX \\ United Kingdom \\ T: +44 1524594215 \\ F: +44 1524594244 \\ E: G.Johnes@lancaster.ac.uk \\ John Ruggiero \\ Department of Economics and Finance \\ University of Dayton \\ 300 College Park \\ Dayton OH 45469-2251 \\ T: +1 9372292550 \\ F: +1 9372292477 \\ E: jruggiero1@udayton.edu
}

April 2016

\begin{abstract}
$\underline{\text { ABSTRACT }}$
A number of studies have considered the evaluation of efficiency in higher education institutions. In this paper we focus on the issue of revenue efficiency, in particular ascertaining the extent to which, given output prices, producers choose the revenue maximising vector of outputs. Following Johnson and Ruggiero (2011), we then relax the price taking assumption to consider the case in which the market for some outputs is characterised by monopolistic competition. We evaluate efficiencies for English institutions of higher education for the academic year 2012-13 and find considerable variation across institutions in revenue efficiency. The relaxation of the price taking assumption leads to relatively small changes, in either direction, to the estimated revenue efficiency scores. A number of issues surrounding the modelling process are raised and discussed, including the determination of the demand function for each type of output and the selection of inputs and outputs to be used in the model.
\end{abstract}

Keywords: efficiency, revenue, monopolistic competition, higher education JEL classifications: C44, D24, D43, I21, I23

Without implication, the authors thank three anonymous referees, participants at the November 2015 LEER conference on Efficiency in Education and the Use of Big Data, and in particular Lori Taylor and Kristof de Witte for useful comments on an earlier draft. 


\section{Introduction}

The evaluation of efficiency comes in many different flavours. The seminal work of Farrell (1957) evolved in contributions by Boles (1971) and Førsund and Hjalmarsson (1974) to produce the workhorse model of data envelopment analysis (DEA) popularised by Charnes et al. (1978). An early refinement of this model introduced consideration of variable returns to scale (Banker et al., 1984) - the so-called BCC model. Meanwhile, building on the early contribution of Leibenstein (1966), Färe et al. (1994) developed a host of linear programming methods that allowed investigation of further aspects of efficiency, in particular introducing prices and the notion of allocative efficiency into the model.

These techniques have come into widespread use, particularly in contexts where production is complex, involving a multiplicity of inputs and outputs, and where - as is common in public service settings - producers are heterogeneous in terms of their objectives. One such area is that of higher education, where different providers vary in the weights they attach to different outcomes that are of relevance to society - teaching and research in a variety of subject areas. The analysis of efficiency in this sector is facilitated by the existence of good data sources. It is not surprising, therefore, that we have witnessed a proliferation of studies concerning the efficiency of universities (Athanassopoulos and Shale, 1997; Agasisti and Johnes, 2009; Agasisti, 2011).

These studies have, however, typically focused on technical and scale efficiency, and have not been extended to examine allocative efficiency. This has been largely due to data limitations. To examine the extent to which institutions are responding appropriately to market signals in choosing their output vectors we need data on prices, in particular on tuition fees. Official data sets have not routinely reported this information. Our aim in the present paper is to exploit a new source of such data for universities in England, namely the Reddin Tuition Fee Survey. ${ }^{1}$ This allows us to consider allocative efficiency using the model of Färe et al. (1994, p.113). We go further, however, by considering the possibility that universities might, in at least some of the markets in which they operate, be price makers rather than price takers. The Färe et al. (1994) model implicitly assumes perfect competition; more recent work, by Johnson and Ruggiero (2011) allows the possibility that there is monopolistic competition so that producers face downward sloping demand curves for their output. This means that, in adjusting their output vectors, they must, when seeking to maximise their revenue, take into account the impact that this has on the prices that they can charge. We know from the literature (see, for example, Gallet, 2007) that the demand for the output of a typical higher education institution has some measure of price sensitivity, and so it is appropriate to accommodate this feature into our models, and into our evaluation of institutions' efficiency.

The paper proceeds as follows. In the next section, we describe the linear programming models that will be used to evaluate the various efficiency measures of interest. In section 3, we introduce the sources of data used. This is followed by an analytical section in which results are presented and discussed. The paper ends with a conclusion and suggestions for further research.

\footnotetext{
${ }^{1}$ Mike Reddin, a lecturer in social policy at the LSE, compiled information about university tuition fees from 2002 onwards. Since his death in 2011, the data have been compiled by the Complete University Guide, one of the producers of university rankings in the UK. Participation in the survey is voluntary for the universities, and has increased sharply in recent years. So, while the survey itself has quite a long history, it is only recently that the data have become useful for an exercise of the type attempted here.
} 


\section{Modelling strategy}

DEA models involve evaluating the relative efficiency of producers or 'decision making units' that employ multiple inputs to produce multiple outputs. The method is non-parametric in that the objective for each producer is optimised by selection of a producer-specific vector of weights on inputs and outputs.

The primal of an output-oriented DEA involves solving a set of linear programs that choose, separately for each decision making unit, values of input and output weights to minimise the weighted sum of inputs required to produce given output, subject to the constraint that the weights chosen should not for any unit imply that the ratio of weighted output to weighted input exceeds one. The BCC variant of the model adds a further constraint to allow identification of inefficiencies due to operation at scale that is below or above the optimum. In its dual form, the linear programming problem is given by

$E_{i}=\max _{\lambda, \theta} \theta$

$$
\begin{array}{lll}
\text { s.t. } & \sum_{l=1}^{N} \lambda_{l} y_{l j} \geq \theta y_{i j} & j=1, \ldots, S \\
& \sum_{l=1}^{N} \lambda_{l} x_{l k} \leq x_{i k} & k=1, \ldots, M \\
& \sum_{l=1}^{N} \lambda_{l}=1 & \\
& \lambda_{l} \geq 0 \quad \forall l=1, \ldots, N . &
\end{array}
$$

where $i=1, \ldots, N$ are the producers, each of which $M$ inputs, $x_{1}, \ldots, x_{M}$, to produce $S$ outputs, $y_{1}, \ldots, y_{s}$.

Note that this problem does not involve any consideration of prices. If producers face prices for their inputs and outputs that differ from the (producer-specific) weights that are the solution to the linear programming problem, then an apparently efficient producer will likely produce quantities of output that do not serve to maximise its revenue. The problem of revenue maximisation has been addressed by Färe et al. (1994, p.113) for the case in which the ith producer faces prices for its outputs given by $p_{i}=\left(p_{i 1}, \ldots, p_{i s}\right)$. Given its production technology, this producer will maximise its revenue by solving the problem

$$
\begin{array}{lll}
R^{*}{ }_{i}= & \max _{y_{j}, \lambda} \sum_{j=1}^{S} p_{i j} y_{j} & \\
\text { s.t. } & \sum_{l=1}^{N} \lambda_{l} y_{l j} \geq y_{j} & \\
& \sum_{l=1}^{N} \lambda_{l} x_{l k} \leq x_{i k} & \\
& \sum_{l=1}^{N} \lambda_{l}=1 & \\
& \lambda_{l} \geq 0 \quad \forall l=1, \ldots, S
\end{array}
$$


The ratio $R_{i}^{*} / \sum_{j=1}^{S} \quad p_{i j} y_{i j} \geq 1$ is a measure of the output revenue efficiency. A score of 1 indicates that the producer is revenue efficient, while scores in excess of 1 indicate allocative inefficiency; in this case switching activity from one output to another, given inputs, could yield higher than outturn revenues.

A variety of models has been developed that pursue further the concept of revenue efficiency. Some of these focus on directional distance functions, in some cases employing slacks-based measures (Aparicio et al., 2013, 2015; Sahoo et al., 2014; Tone, 2002). Others (such as Mozaffari et al., 2014) compare conventional DEA methods with a ratio approach that imposes more structure on the models; in practice these approaches appear to have only a minor effect on measured efficiency. Meanwhile, Oliveira et al. (2013) eschew the nonparametric approach altogether in order to analyse revenue efficiency using a stochastic frontier.

Here, however, we consider the Johnson and Ruggiero (2011) model that notes the implicit assumption of the Färe et al. (1994) model that producers are price takers may not hold good in practice. In particular, firms may, for some of their outputs at least, face a downward sloping demand schedule; if they raise their price, consumers may transfer their custom to another producer. This would, for example, be in line with a market structure characterised by monopolistic competition. ${ }^{2}$ In the context of English higher education institutions, we note that providers have discretion over the tuition fees they charge in particular for overseas students - and so in the analysis that follows we shall assume a downward sloping demand curve for such students (while continuing to assume that institutions are price takers for students from the United Kingdom and other EU countries). The Johnson and Ruggiero (2011) model is given by

$$
\begin{array}{lll}
R_{i}^{*}= & \max _{y_{j}, \lambda} \sum_{j=1}^{S} p_{i j}\left(y_{j}\right) y_{j} & \\
\text { s.t. } & \sum_{l=1}^{N} \lambda_{l} y_{l j} \geq y_{j} & \\
& \sum_{l=1}^{N} \lambda_{l} x_{l k} \leq x_{i k} & \\
& \sum_{l=1}^{N} \lambda_{l}=1 & \\
& \lambda_{l} \geq 0 \quad \forall l=1, \ldots, S
\end{array}
$$

This requires precise specification of the inverse demand function, $p_{i j}\left(y_{j}\right)$, faced by each institution for each output for which the institution is not a price taker. While estimates of the own price elasticity of demand for higher education vary across studies, we use -0.8 as a central estimate, and later check the robustness of our results to variation in this figure (Wohlgemuth, 2013; Langella, 2016). We then construct a linear demand function for the ith provider and the $j$ th output that passes through the observed price-quantity pairing and that has elasticity of -0.8 at this point. So for each output type, different demand curves are faced by different institutions; this is attributed to secular shift factors. Hence the inverse demand curve for the $j$ th output produced by the ith institution is given by

\footnotetext{
${ }^{2}$ Markets may plausibly be oligopolistic rather than monopolistically competitive, of course, though the modelling in the case of such market structures would be complicated by interdependence.
} 
where $p_{0 i j}$ and $y_{0 i j}$ represent the (given) observed values of price and output respectively. Clearly any number of alternative assumptions could conceivably be made about the shape of the demand functions, and, given heterogeneity across institutions, there is no straightforward way of estimating a unique demand curve along which all observations will lie. Note also that, in (4), we have made $p_{i j}$ a function of $y_{i j}$, rather than of $y_{j}$ as in (3). We therefore consider the results based upon our preferred assumption to be instructive but illustrative. ${ }^{3}$

Once the above programming problem has been solved, the output revenue efficiency associated with the Johnson and Ruggiero (2011) model can be calculated in an analogous fashion to that used in the context of the Färe et al. (1994) model.

\section{Data}

The richness of higher education institutions as producers derives from the multiplicity of outputs produced; indeed the term 'university' reflects the provision by a single entity of expertise drawn from the full range of knowledge. Many studies thus focus on teaching and research as distinct outputs. In the present exercise, we focus rather on the various types of teaching provision, and include also research activity, measured by the level of grant income supporting research projects.

Teaching is undertaken at a variety of levels (undergraduate, postgraduate) in a variety of subject areas (which have different implications for costs - classroom based subjects, laboratory based subjects, mixed subjects, clinical subjects) and to students from a variety of backgrounds. In England, tuition fees may be set at different levels for students based in the United Kingdom and in the rest of the European Union (EU), on the one hand, and for students based outside the EU (so-called 'overseas' students) on the other.

While we have data on student numbers and tuition fees for clinical medicine, we exclude these from the analysis that follows - that is, we do not include clinical students as outputs, and we subtract expenditure on them from the data on university spending - because many universities have no provision in this subject area at all. The linear programming methods used in the present paper fail if there are zeros in the data, so it would not be possible to evaluate models in which both universities that provide tuition in the clinical subject areas and those that do not appear.

Institutions are free to set tuition fees at whatever level they choose for overseas students. Typically they charge different fees for different subjects. We therefore consider as separate outputs overseas students in classroom based subjects, laboratory based subjects and mixed subjects. We separate these out into those studying for undergraduate and those studying for postgraduate degrees. In addition to these six outputs, we consider two further teaching outputs: home and EU (HEU) undergraduate students and HEU postgraduate students. Finally we consider research activity (measured by research grants) as an output.

\footnotetext{
${ }^{3}$ Johnson and Ruggiero (2011) provide a stylised example of how their model might work in practice, calculating revenue efficiency for just one decision making unit. A contribution of the present paper is to operationalise their method by introducing the assumption that the demand function for each output type applies to institutions with a shifter due to institutional heterogeneity.
} 
Institutions may charge tuition fees of up to $£ 9000$ per year to HEU undergraduates; because of technicalities within the funding mechanism, most charge the full $£ 9000$ to all students, regardless of subject of study. ${ }^{4}$ We do not, therefore, separate out HEU students by subject area. Furthermore, while institutions are able to differentiate their fees by subject for HEU postgraduates, we consider these too to be a single output; they are relatively small in number, and, in particular for those undertaking doctoral study, many universities choose to set tuition fees close to or at levels that are reimbursed by research councils. When evaluating the Johnson and Ruggiero (2011) model, we shall assume that institutions face a downward sloping demand function for the six outputs that measure overseas students, but that they are price takers for HEU students and research.

We assume that these nine outputs are produced using a single input, namely expenditure (minus, as noted above, spending on provision in clinical subject areas). While the sample of universities is not particularly large, the rule of thumb that the number of observations in a DEA exercise should equal at least $\max \{\mathrm{MS}, 3(\mathrm{M}+\mathrm{S})\}$ is comfortably met (Cooper et al., 2007, p.116).

All data used in the present study refer to English higher education institutions in the academic year 2012-13. This is, at the time of writing, the latest year for which data on student numbers and finance are available; these data come from the official publications of the Higher Education Statistics Agency (HESA), respectively Students in Higher Education Institutions and Finances of Higher Education Institutions. Student numbers refer to full-time equivalent numbers, obtained by attaching a 0.5 weight to part-time students. Data on the numbers of overseas students by institution and by subject area are unpublished, and were obtained by direct request to HESA. The data on tuition fees are obtained from the Reddin survey. ${ }^{5}$

As noted earlier, the Reddin data do not cover all institutions, but they do represent the only opportunity, at this stage, to use price data to evaluate allocative efficiency in English higher education. ${ }^{6}$ Table 1 reports descriptive statistics for the main variables used in our analysis. The scale of institutions, as measured by the standard deviations of the student numbers and costs variables relative to the corresponding means, clearly varies considerably within the sample. It is instructive to compare the descriptive statistics with the broad characteristics of the population of higher education institutions in England - for which the average number of undergraduates and postgraduates were 10234 and 2674 respectively in 2012-13. These figures are slightly lower than those reported in Table 1, but the discrepancy is not large enough to suggest that our sample is anything other than representative of the population of institutions.

\footnotetext{
${ }^{4}$ Students receive an income-contingent loan that enables them to pay the tuition fees. Repayments are made through the tax system once the student has graduated and earns over a threshold level of annual income. Graduates continue repaying until their loan is paid off, or until it is written off. The latter happens 30 years after graduation, the cost of this falling on the taxpayer. Many prospective students will not expect to repay the full value of their loan, and so are indifferent between tuition fees of $£ 9000$ per annum or less. Since the institutions receive the full tuition fee, they have the incentive to charge up to the limit.

${ }^{5}$ For a small number of institutions, the Reddin data do not report tuition fees for overseas students in mixed subjects; for these cases, fees are assumed equal to those charged for classroom based subjects. Likewise, in a small number of cases, fees are presented as a range; in these cases the mid-point has been used.

6 Three institutions, University College Birmingham, Canterbury Christ Church University and Newman Univeristy, appear in the Reddin data but are not in the sample of institutions investigated here. They are excluded from our sample because they report zero values of some outputs.
} 
The sample includes institutions of various vintages. Neither of the ancient universities (Oxford and Cambridge) is in the data, but older civic universities in the 'Russell Group' of elite institutions are. These include, for example, Manchester, Nottingham and Newcastle. The sample also includes smaller research intensive universities created in the 1960s. Many of these were formerly members of the 1994 Group of universities. They include 'greenfield' institutions such as Essex and the University of East Anglia, and also former Colleges of Advanced Technology such as Loughborough and Surrey. In 1992, numerous institutions were converted from polytechnics to universities; these retain a strong teaching focus, but are increasingly engaged in research, often of an applied nature. In our sample, examples of such institutions include Manchester Metropolitan, Nottingham Trent, and Oxford Brookes. Finally, a new wave of institutions that attained university status in the current century is represented in our data by Bolton, Southampton Solent and Winchester.

\section{Results}

The three models discussed above have been evaluated using an amended version of the SAS program that is reproduced in Blackburn et al. (2014, ch.2.4). The results appear in Table 2.

The BCC efficiency scores suggest a high level of efficiency across the institutions in our sample. Indeed, some 28 of the 40 institutions have scores of unity. Of the remainder, most are close to one. The highest score is for Loughborough, at 1.21. There is no systematic variation across type of institution as defined by vintage.

The results suggest that institutions that appear to be technically efficient as defined by the BCC model can nonetheless suffer from quite high levels of revenue inefficiency as evaluated by the Färe et al. (1994) measure. Several London institutions - City, Goldsmiths, and the LSE - stand out in this respect. Their positions within a system of institutions in a large urban area may compromise the extent to which they can make choices about subject mix. A fourth London institution, Queen Mary College, also has a revenue inefficiency score that is high in relation to its score on the BCC measure. Taking this institution as an example, it is instructive to observe how the efficient levels of output, calculated using the Färe et al. (1994) method, differ from the outturn. The institution would maximise efficiency by taking on (considerably) more HEU undergraduate students and HEU postgraduates, and by admitting fewer overseas students (in all categories except postgraduates in classroom based subjects). There are, of course, constraints that prevent the institution from doing this in practice. In particular, until 2015-16, institutions faced regulatory controls that prevented them from choosing the number of HEU undergraduates that they could recruit.

Indeed, if we examine the 12 least revenue efficient institutions on the Johnson and Ruggiero (2011) measure - all of which are pre-1992 institutions - the efficient output vector implies that they should enrol an average of 21499 HEU undergraduates (see Table 3). This compares with an outturn of just 7803. By way of contrast, the five universities that are most revenue efficient - which include two of the largest three institutions in the country (Manchester Metropolitan and Manchester) enrol an average of 13611 HEU undergraduates - very close to the level that maximises revenue for these universities. We might therefore expect the impact of the removal of the cap on student numbers to be, over time, substantial growth in 
HEU undergraduate numbers in the least revenue efficient institutions - typically smaller, research intensive, universities. ${ }^{7}$

As a whole, the Johnson and Ruggiero (2011) efficiencies are not hugely different from those obtained using the Färe et al. (1994) measure. To a large extent this is because we are assuming institutions to be price takers for HEU students, and these represent the majority of students. It might also, however, be due to the assumption made about the price elasticity of demand; while our assumption is in line with estimates drawn from the literature, it is instructive to consider what the results might look like if alternative assumptions are made. To this end, we report, in Table 4, the Johnson and Ruggiero (2011) efficiencies that are obtained when the assumption of a demand elasticity of -0.8 is replaced by assuming a figure of -0.5 . As is readily observed the inefficiency scores typically rise, but the increase is small.

Given the relatively inelastic nature of demand at the observed price and output values, it is always the case that, in the Johnson and Ruggiero (2011) model, the prices associated with revenue efficiency exceed the outturn prices for those outputs facing a downward sloping demand schedule. This may or may not imply that the output levels themselves are lower than are implied by efficiency in the Färe et al. (1994) model. In most situations, the Johnson and Ruggiero (2011) levels of efficient output are lower than is the case in the Färe et al. (1994) model. But in cases where the efficient level of production of a particular output type is, according to the Färe et al. (1994) model, lower than the outturn output, the price-output pairing is below the demand schedule and it is therefore possible that the optimal pairing suggested by the Johnson and Ruggiero (2011) model involves both a higher price and higher output.

\section{Conclusion}

To the best of our knowledge, this paper represents the first attempt to evaluate the revenue efficiency of institutions of higher education. This supplements what we already know about technical and scale efficiency by providing further information about allocative efficiency, grafting onto existing information sets data on prices. Some institutions that appear to be good performers, relative to their peers, in terms of scale and technical efficiency are seen to be less successful at ensuring that their inputs are directed in an optimal fashion toward the production of outputs that, given prices, are most remunerative. This analysis might therefore serve to steer such institutions in the direction of more revenue efficient behaviour. We do not suggest that institutions are necessarily revenue maximisers; rather we use the revenue maximisation model as a means of ascertaining how closely each institution's behaviour matches that of a revenue maximiser.

In conducting this analysis, we have recognised that institutions are not necessarily price takers in connection with all types of output that they produce. Building on the work of Johnson and Ruggiero (2011), we have examined the implications for revenue efficiency measures of assuming that institutions face downward sloping demand curves for (most of) their outputs. In practice the effects appear to be quite small, but we acknowledge that this

\footnotetext{
${ }^{7}$ A similar finding, suggesting that universities may switch activity from postgraduate to undergraduate following the raising of the cap on HEU undergraduate tuition fees, is due to Johnes (2014).
} 
might be the result of the specific assumptions employed here. Further research is therefore warranted.

\section{References}

Agasisti, Tommaso (2011) Performances and spending efficiency in higher education: a European comparison through non-parametric approaches, Education Economics, 19, 199224.

Agasisti, Tommaso and Geraint Johnes (2009) Beyond frontiers: comparing the efficiency of higher education decision making units across more than one country, Education Economics, 17, 59-79.

Aparicio, Juan, Fernando Borras, Jesus T. Pastor and Fernando Vidal (2013) Accounting for slacks to measure and decompose revenue efficiency in the Spanish designation of origin wines with DEA, European Journal of Operational Research, 231, 443-451.

Aparicio, Juan, Fernando Borras, Jesus T. Pastor and Fernando Vidal (2015) Measuring and decomposing firm's revenue and cost efficiency: the Russell measures revisited, International Journal of Production Economics, 165, 19-28.

Athanassopoulos, Antreas D. and Estelle Shale (1997) Assessing the comparative efficiency of higher education institutions in the UK by means of data envelopment analysis, Education Economics, 5, 117-134.

Banker, Rajiv, Abraham Charnes and William W. Cooper (1984) Some models for estimating technical and scale inefficiencies in data envelopment analysis, Management Science, 30, 1078-1092.

Blackburn, Vincent, Shae Brennan and John Ruggiero (2014) Nonparametric Estimation of Educational Production and Costs using Data Envelopment Analysis, New York: Springer.

Boles, James Newton (1971) The 1130 Farrell efficiency system: multiple products, multiple factors, Giannini Foundation of Agricultural Economics, University of California, Berkeley.

Charnes, Abraham, William W. Cooper and Eduardo Rhodes, (1978) Measuring the efficiency of decision making units, European Journal of Operational Research, 2, 429-444.

Cooper, William W., Lawrence M. Seiford and Kaoru Tone (2007) Data Envelopment Analysis, New York: Springer.

Färe, Rolf, Shawna Grosskopf and C.A.Knox Lovell (1994) Production Frontiers, Cambridge: Cambridge University Press.

Farrell, Michael J. (1957) The measurement of productive efficiency, Journal of the Royal Statistical Society A, 120, 253-290. 
Førsund, Finn R. and Lennart Hjalmarsson (1974) On the measurement of the productive efficiency, Swedish Journal of Economics, 76, 141-154.

Gallet, Craig (2007) A comparative analysis of the demand for higher education: results from a meta-analysis of elasticities, Economics Bulletin, 9(7), 1-14.

Johnes, Jill (2014) Efficiency and input substitutability in English higher education 1996-7 to 2008-9, Paper presented at INFORMS conference, San Francisco, http://eprints.hud.ac.uk/23955/1/INFORMS\%20San\%20Franciso\%20November\%202014.pdf

Johnson, Andrew L. and John Ruggiero (2011) Allocative efficiency measurement with endogenous prices, Economics Letters, 111, 81-83.

Langella, Monica (2016) University costs and university particulation: evidence from the UK, Paper delivered at the Royal Economic Society Conference, https://editorialexpress.com/cgi-

bin/conference/download.cgi?db_name=RESConf2016\&paper_id=939.

Leibenstein, Harvey (1966) Allocative efficiency versus x-efficiency, American Economic Review, 56, 392-415.

Mozaffari, Mohammad Reza, Parisa Kamyab, Josef Jablonsky and Javad Gerami (2014) Cost and revenue efficiency in DEA-R models, Computers and Industrial Engineering, 78, 188194.

Oliveira, Ricardo, Maria Isabel Pedro and Rui Cunha Marques (2013) Efficiency performance of the Algarve hotels using a revenue function, International Journal of Hospitality Management, 35, 59-67.

Sahoo, Biresh K., Mahmood Mehdiloozad and Kauro Tone (2014) Cost, revenue and profit efficiency measurement in DEA: a directional distance function approach, European Journal of Operational Research, 237, 921-931.

Tone, Kauro (2002) A strange case of the cost and allocative efficiencies in DEA, Journal of the Operational Research Society, 53, 1225-1231.

Wohlgemuth, Darin (2013) Estimating the market demand and elasticity for enrolment at an institution, Strategic Enrollment Management Quarterly, 1, 67-74. 
Table 1: Descriptive statistics (numbers of students, £’000)

\begin{tabular}{lcc}
\hline Costs & 237601 & \\
& $(176067)$ & \\
\hline Research & 46159 & \\
& $(80437)$ & \\
\hline HEU undergraduate & Student numbers & Tuition fees \\
& 12653 & 8.697 \\
HEU postgraduate & $(5587.9)$ & $(0.468)$ \\
& 2489.1 & 6.201 \\
OS undergraduate (class) & $(1585.0)$ & $(2.314)$ \\
& 757.67 & 11.282 \\
OS undergraduate (mixed) & $(474.27)$ & $(2.384)$ \\
& 316.96 & 11.614 \\
OS undergraduate (lab) & $(248.59)$ & $(2.384)$ \\
& 363.86 & 13.012 \\
OS postgraduate (class) & $(419.69)$ & $(3.118)$ \\
& 840.58 & 11.763 \\
OS postgraduate (mixed) & $(645.07)$ & $(2.288)$ \\
& 274.95 & 12.133 \\
OS postgraduate (lab) & $(268.58)$ & $(2.483)$ \\
& 344.13 & 13.570 \\
& $(406.53)$ & $(3.394)$ \\
\hline
\end{tabular}

Note: The table reports averages, with standard deviations in parentheses. 
Table 2: Efficiency scores

\begin{tabular}{|c|c|c|c|}
\hline University & BCC & Färe et al & Johnson \& Ruggiero \\
\hline Birmingham & 1.00 & 1.11 & 1.09 \\
\hline Bolton & 1.00 & 1.00 & 1.00 \\
\hline Bournemouth & 1.01 & 1.13 & 1.06 \\
\hline Bradford & 1.14 & 1.37 & 1.31 \\
\hline UCLAN & 1.00 & 1.04 & 1.05 \\
\hline City & 1.00 & 1.63 & 1.68 \\
\hline Coventry & 1.00 & 1.08 & 1.13 \\
\hline Derby & 1.14 & 1.34 & 1.24 \\
\hline Durham & 1.10 & 1.42 & 1.45 \\
\hline East Anglia & 1.00 & 1.43 & 1.47 \\
\hline Essex & 1.00 & 1.30 & 1.32 \\
\hline Goldsmiths & 1.00 & 1.63 & 1.42 \\
\hline Hull & 1.00 & 1.22 & 1.25 \\
\hline Imperial & 1.00 & 1.15 & 1.00 \\
\hline Kent & 1.00 & 1.23 & 1.27 \\
\hline Leeds Beckett & 1.00 & 1.04 & 1.02 \\
\hline Leeds & 1.00 & 1.08 & 1.02 \\
\hline Lincoln & 1.10 & 1.30 & 1.18 \\
\hline LSE & 1.00 & 1.72 & 1.76 \\
\hline Loughborough & 1.21 & 1.49 & 1.51 \\
\hline Manchester Metropolitan & 1.00 & 1.00 & 1.00 \\
\hline Manchester & 1.00 & 1.00 & 1.00 \\
\hline Middlesex & 1.00 & 1.20 & 1.22 \\
\hline Newcastle & 1.03 & 1.19 & 1.23 \\
\hline Northumbria & 1.00 & 1.14 & 1.18 \\
\hline Nottingham Trent & 1.00 & 1.05 & 1.07 \\
\hline Nottingham & 1.00 & 1.00 & 1.03 \\
\hline Oxford Brookes & 1.04 & 1.38 & 1.39 \\
\hline Plymouth & 1.00 & 1.05 & 1.07 \\
\hline Portsmouth & 1.00 & 1.13 & 1.16 \\
\hline Queen Mary College & 1.12 & 1.44 & 1.44 \\
\hline Salford & 1.09 & 1.33 & 1.33 \\
\hline Sheffield & 1.00 & 1.11 & 1.13 \\
\hline Southampton Solent & 1.00 & 1.33 & 1.22 \\
\hline Sunderland & 1.00 & 1.28 & 1.33 \\
\hline Surrey & 1.07 & 1.61 & 1.67 \\
\hline Sussex & 1.06 & 1.48 & 1.51 \\
\hline UCL & 1.00 & 1.00 & 1.00 \\
\hline West London & 1.00 & 1.00 & 1.02 \\
\hline Winchester & 1.00 & 1.20 & 1.13 \\
\hline
\end{tabular}


Table 3 Revenue efficient numbers of HEU undergraduates, selected institutions

\begin{tabular}{lcc}
\hline University & Revenue efficient & Outturn \\
\hline City & 21257 & 6860 \\
Durham & 24340 & 10598 \\
East Anglia & 23367 & 9987 \\
Goldsmiths & 9142 & 4210 \\
LSE & 24520 & 2487 \\
Loughborough & 24524 & 10503 \\
Queen Mary College & 24130 & 9465 \\
Surrey & 22317 & 7945 \\
Sussex & 19892 & 8168 \\
& & \\
Bolton & 4975 & 4975 \\
Imperial & 8506 & 6460 \\
Manchester Metropolitan & 24525 & 24525 \\
Manchester & 18803 & 21855 \\
UCL & 10240 & 10240 \\
\hline
\end{tabular}

Note: The revenue efficient numbers for Imperial and Manchester differ from the outturn because, before rounding, the revenue efficiency for these institutions is greater than one. 
Table 4 Johnson and Ruggiero efficiency scores with alternative elasticity assumption

\begin{tabular}{lclc}
\hline University & Efficiency score & University & Efficiency score \\
\hline Birmingham & 1.12 & Manchester Metropolitan & 1.01 \\
Bolton & 1.01 & Manchester & 1.03 \\
Bournemouth & 1.07 & Middlesex & 1.26 \\
Bradford & 1.33 & Newcastle & 1.25 \\
UCLAN & 1.06 & Northumbria & 1.20 \\
City & 1.72 & Nottingham Trent & 1.09 \\
Coventry & 1.17 & Nottingham & 1.06 \\
Derby & 1.25 & Oxford Brookes & 1.41 \\
Durham & 1.48 & Plymouth & 1.08 \\
East Anglia & 1.50 & Portsmouth & 1.18 \\
Essex & 1.34 & Queen Mary College & 1.46 \\
Goldsmiths & 1.45 & Salford & 1.34 \\
Hull & 1.28 & Sheffield & 1.17 \\
Imperial & 1.02 & Southampton Solent & 1.24 \\
Kent & 1.30 & Sunderland & 1.37 \\
Leeds Beckett & 1.03 & Surrey & 1.71 \\
Leeds & 1.04 & Sussex & 1.56 \\
Lincoln & 1.19 & UCL & 1.02 \\
LSE & 1.80 & West London & 1.06 \\
Loughborough & 1.53 & Winchester & 1.14 \\
\hline
\end{tabular}

